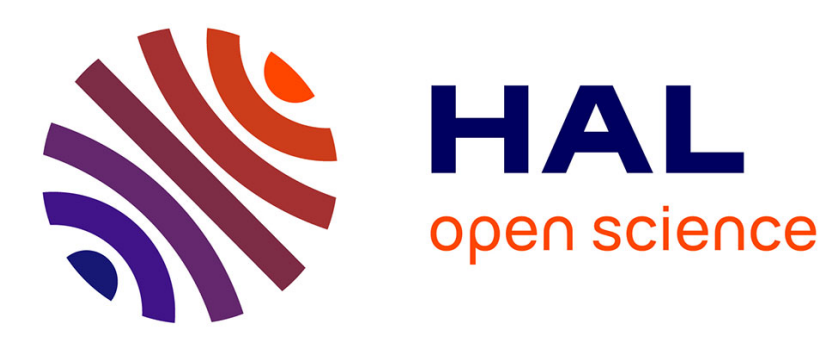

\title{
Thermodynamic Calculations for Studying High Temperature Oxidation of Superalloys
}

\author{
P. Berthod, S. Michon, J. Di Martino, S Mathieu, S. Noël, R Podor, C Rapin
}

\section{To cite this version:}

P. Berthod, S. Michon, J. Di Martino, S Mathieu, S. Noël, et al.. Thermodynamic Calculations for Studying High Temperature Oxidation of Superalloys. Calphad, 2003, 10.1016/j.calphad.2003.12.002 . hal-02398209

\section{HAL Id: hal-02398209 \\ https://hal.science/hal-02398209}

Submitted on 7 Dec 2019

HAL is a multi-disciplinary open access archive for the deposit and dissemination of scientific research documents, whether they are published or not. The documents may come from teaching and research institutions in France or abroad, or from public or private research centers.
L'archive ouverte pluridisciplinaire HAL, est destinée au dépôt et à la diffusion de documents scientifiques de niveau recherche, publiés ou non, émanant des établissements d'enseignement et de recherche français ou étrangers, des laboratoires publics ou privés. 


\title{
Thermodynamic Calculations for Studying High Temperature Oxidation of Superalloys
}

\author{
P. Berthod*, S. Michon, J. Di Martino, S. Mathieu, S. Noël, R. Podor, C. Rapin \\ Laboratoire de Chimie du Solide Minéral (UMR 7555), Université Henri Poincaré \\ BP 239, 54506 Vandoeuvre-lès-Nancy - France \\ * Corresponding author's e-mail : patrice.berthod@centraliens-lille.org
}

Post-print version of the article Calphad, Vol.27, pp. 279-288 (2003); doi:10.1016/j.calphad.2003.12.002

\begin{abstract}
Microstructure phenomena resulting from high temperature oxidation of a simple nickel alloy and two cobalt-base superalloys were studied by microstructure examinations and thermodynamic calculations. The latter allowed to better quantify what happened to carbon during oxidation, which was not possible with microstructure examination and microanalysis alone, and to explain the microstructure changes due to oxidation. At $1000^{\circ} \mathrm{C}$, due to the $\mathrm{Cr}$ oxidation, the grain boundary carbides dissolve and the carbon diffuses inwards, where new carbides form. However, at 1100 and $1200^{\circ} \mathrm{C}$, the carbon diffuses outwards to the surface. Thermodynamic calculations were used to explain the seemingly different mechanisms of carbon diffusion.
\end{abstract}

\section{Introduction}

When superalloys are oxidized at high temperatures, oxide scales grow on their surface. Aluminum and/or chromium are precisely added to the alloys in order to form a continuous oxide layer over the surface of the alloy. During oxidation, this layer acts as a protective layer since chromia $\left(\mathrm{Cr}_{2} \mathrm{O}_{3}\right)$ and alumina $\left(\mathrm{Al}_{2} \mathrm{O}_{3}\right)$ are stoichiometric oxides, without many defects such as interstitial atoms or vacancies that could help ions diffusion. Thus the oxidation rate remains low. Other reactive elements such as titanium or tantalum, when present, can also participate in the formation of oxides [1,2].

During oxidation, many of these elements diffuse towards the oxidation front $[3,4]$. When temperature and/or time exposition are high enough, concentration gradients appear. This evolution of the local chemical composition can lead to microstructure modifications. Figure 1 illustrates, for example, the case of an industrial piece after working at nearly $1000^{\circ} \mathrm{C}$ for a long time (several hundreds hours). Its microstructure is modified by the disappearance of the initial carbides from the affected zone, and by the precipitation of new acicular phases a little deeper. While it is generally easy to detect where metallic elements from disappearing phases have gone, it is much more difficult for other constitutive elements. For instance, when chromium carbides dissolve, the carbon can diffuse towards the oxidation front to be oxidized by air into $\mathrm{CO}$ or $\mathrm{CO}_{2}$, or can go back into the matrix. However, carbon is particularly difficult to analyze by microprobe since it is a light element and its amount in most superalloys is very small. Fortunately, in addition to the microstructure examinations, microanalysis of heavier elements, thermodynamic calculations can help to understand where light elements have gone, to better describe the oxidation phenomena or its consequences on the microstructure.

\section{Experimental Method}

\section{Characteristics of the Alloys Studied}

Superalloys are often used as structural parts in aeronautics or hot industrial processes for temperatures higher than $1000^{\circ} \mathrm{C}$. Generally they are designed to resist high temperature oxidation by gases and hot corrosion by molten salts. For that they contain oxidable elements which promote the external formation of stoichiometric 
refractory oxides that act as a protective layer [5]. The sufficient mechanical properties of superalloys are due to both thin hard precipitates dispersed in the alloy (e.g. $\mathrm{Ni}_{3} \mathrm{Al}$ and secondary carbides) and coarser hard particles like carbides present in grain boundaries.
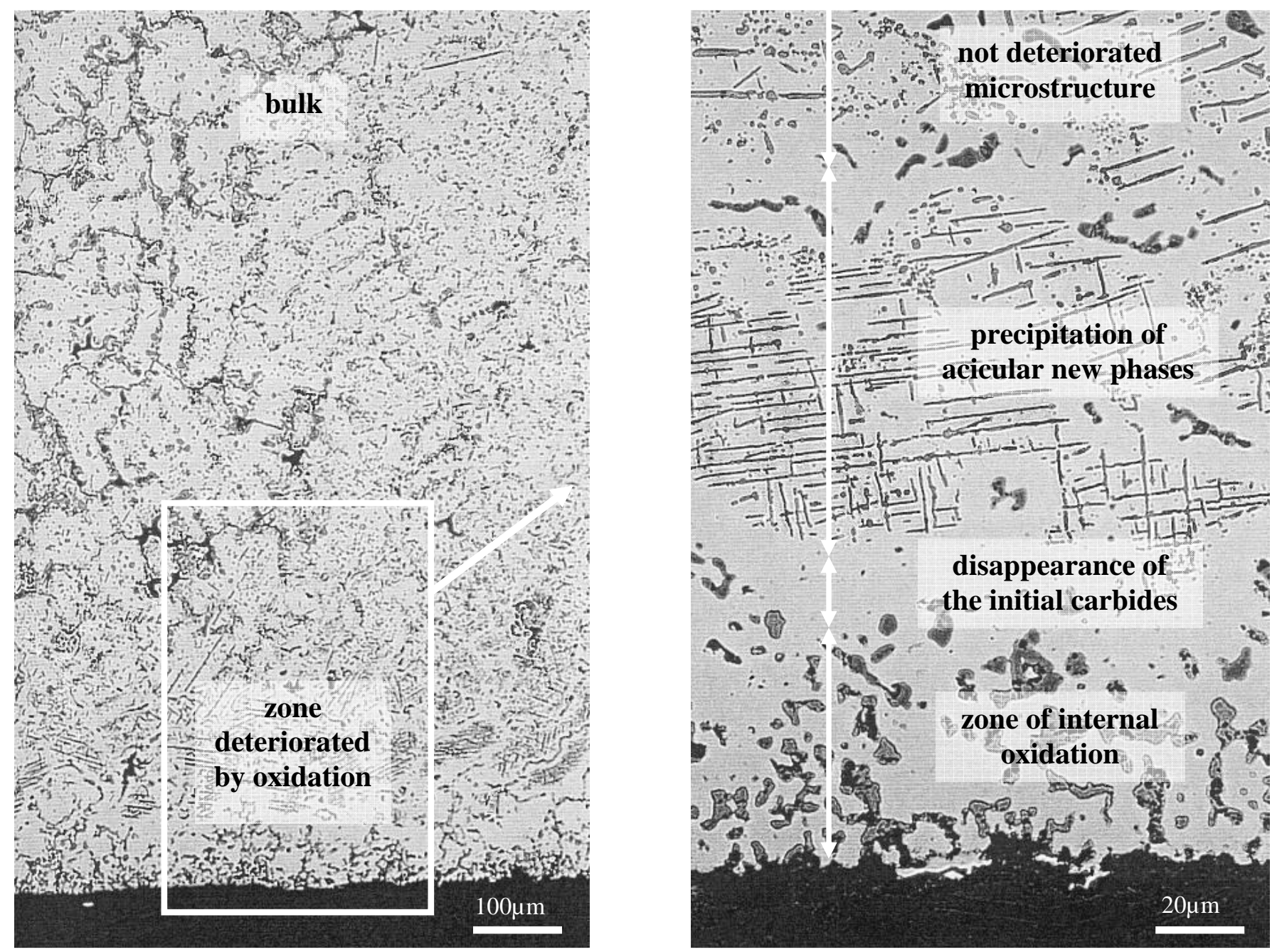

Figure 1 An industrial example of microstructure deterioration during high temperature oxidation (sample observed with an optical microscope after etching)

The alloys studied here are of two types. First there are two cobalt-base superalloys, industrially employed in hot processes. They contain mainly cobalt, chromium and nickel but also tantalum and carbon. In order to easily begin this study, a simple nickel alloy was also synthesized. Table 1 displays the chemical composition of these three alloys.

The simple nickel alloy, called NiA, was synthesized in small quantities by High Frequency induction melting (ingots of nearly 50g) in a copper cold crucible. Cobalt-base superalloys were obtained using a bigger induction furnace (Balzers, capacity of $20 \mathrm{~kg}$ ), under Argon gas. In the latter case the molten alloys were poured and solidified in a sand mold (bonded with an Alphaset resin) in the furnace enclosure. In addition, the two cobalt-base superalloys underwent a homogenization treatment at $1200^{\circ} \mathrm{C}$ for 2 hours, followed by a stage at $1000^{\circ} \mathrm{C}$ for 10 hours. Finally they were air quenched. Thus they get a dense and homogeneous precipitation of thin carbides. In all cases, the alloys were synthesized using pure elements. 


\begin{tabular}{|c|c|c|c|c|c|}
\hline Alloys & Co & Ni & Cr & C & Ta \\
\hline NiA & $/$ & bal & 30 & 0.2 & $/$ \\
\hline CoA & bal & 8.5 & 30 & 0.4 & 6 \\
\hline CoB & bal & 8.5 & 30 & 1.0 & 6 \\
\hline
\end{tabular}

\section{High Temperature Oxidation Runs and Microstructure Examinations}

Oxidation tests at high temperatures were performed using two thermobalances. For NiA a Setaram MTB 10-8 was used while the two cobalt base superalloys were tested with a Seteram TG92. The samples were parallelepipeds, the dimensions of which were about $2 \mathrm{~mm} \times 10 \mathrm{~mm} \times 10 \mathrm{~mm}$. The surface was polished with $\mathrm{SiC}$ paper from 80 to 1200 grid under water. Oxidation tests were performed mainly during 100 hours at $1000^{\circ} \mathrm{C}$, and $1100^{\circ} \mathrm{C}$ in some cases, under an industrial air flow at 1.5 liter/hour. After oxidation tests all samples were covered using cathodic evaporation of gold, in order to give a good electrical conductivity to the external oxide layer. Then, the samples were strengthened by an electrolytic deposition of nickel. The samples were cut in two parts using an Accutom-2 saw equipped with a diamond blade, then embedded in a cold resin (Araldite CY230 +Strengthener Escil HY956). Polishing was done, first with SiC paper from 80 to 1200 grid under water, then finished with diamond pastes $6 \mu \mathrm{m}$ and $3 \mu \mathrm{m}$ (DP-Suspension P of Struers).

A Scanning Electron Microscope (SEM) Philips XL30 was used in Back Scattered Electrons (BSE) mode. The constitutive phases can clearly be observed since the average atomic numbers are sensibly different. In addition, some of them were clearly identified by Energy Dispersion Spectrometry (EDS) associated to the SEM, or by Wavelength Dispersion Spectrometry (WDS) using a Cameca SX100 microprobe. Furthermore, SEM was also employed to analyze the mean chemical composition of a selected area over the local microstructure. Microprobe was employed to get concentration profiles through the external zone deteriorated by oxidation.

\section{Image Analysis}

Measurements of the surface fractions of the different phases were realized on SEM photographs (BSE mode), using the AnalySIS software of Soft Imaging System GMBH. The results are surface fractions, from what, assuming that surface fraction and volume fraction have similar values, volume fractions were assessed. Using the equation (1), and using room temperature densities of the different phases, the mass fraction of each phase was estimated.

$$
\mathrm{f}_{\text {mass }}\left(\varphi_{\mathrm{j}}\right)=\frac{\rho_{\varphi_{\mathrm{j}}} \cdot \mathrm{f}_{\mathrm{vol}}\left(\varphi_{\mathrm{j}}\right)}{\sum_{\mathrm{i}}\left(\rho_{\varphi_{\mathrm{i}}} \cdot \mathrm{f}_{\mathrm{vol}}\left(\varphi_{\mathrm{i}}\right)\right)}
$$

The values used for the densities (in $\mathrm{g} . \mathrm{cm}^{-3}$ ) are 8.9 for the matrix, 6.941 for the $\mathrm{Cr}_{7} \mathrm{C}_{3}$ carbide, 6.953 for the $\mathrm{Cr}_{23} \mathrm{C}_{6}$ carbide and 14.5 for the TaC carbide [6].

\section{Thermodynamic Calculations}

Thermodynamic calculations were carried out using Thermo-Calc software [7] with the SSOL database (SGTE) [8]. For the more complex cobalt alloys, the SSOL database was completed with binary and ternary systems : Ta-C [9], Co-Ta [10], Ni-Ta [11], Cr-Ta [12], Co-Ta-C [13], Ni-Cr-Ta [14]. Thereafter, only four ternary systems were still missing in the new database : Co-Cr-Ta, Co-Ni-Ta, Ni-Ta-C and Cr-Ta-C. ThermoCalc calculations have been performed, firstly to verify the good accordance of chemical composition and the stable microstructure at the considered high temperature. Secondly, calculating isothermal or others diagrams for the oxidation zones lead to determine an upper limit for the carbon content, and to calculate the probable carbon content, knowing quantitatively both microstructure and the other elements contents from image analysis and microanalysis. Thirdly, thermodynamic calculation is used to understand why carbon seems to diffuse in different directions at different temperatures. 


\section{Bulk Microstructure after Exposure at $1000^{\circ} \mathrm{C}$ for 100 hours}

Figure 2 shows an example of SEM photograph of the microstructure in the bulk after 100 hours at $1000^{\circ} \mathrm{C}$. Compared to the initial microstructure for which more carbides were present (but still in a metastable state), carbides here are smaller and more dispersed. These carbides were identified as $\mathrm{Cr}_{7} \mathrm{C}_{3}$, microanalysis being able to estimate the carbon content in such carbon rich phases, despite of their small size.

For the whole photographed zone, EDS microanalysis lead to weight contents equal to $29.46 \%$ for chromium, carbon being not detected because of its low content and its low atomic number ; nickel is the balance. Image analysis lead to surface fraction values between $1.72 \%$ surf and $3.58 \%$ surf. The average value, which is of $2.65 \%$ surf $\left(f_{\text {mass }}=2.08 \%\right)$, was obtained by Thermo-Calc for $0.20 \%$ wt $\mathrm{C}(+/-0.1)$.

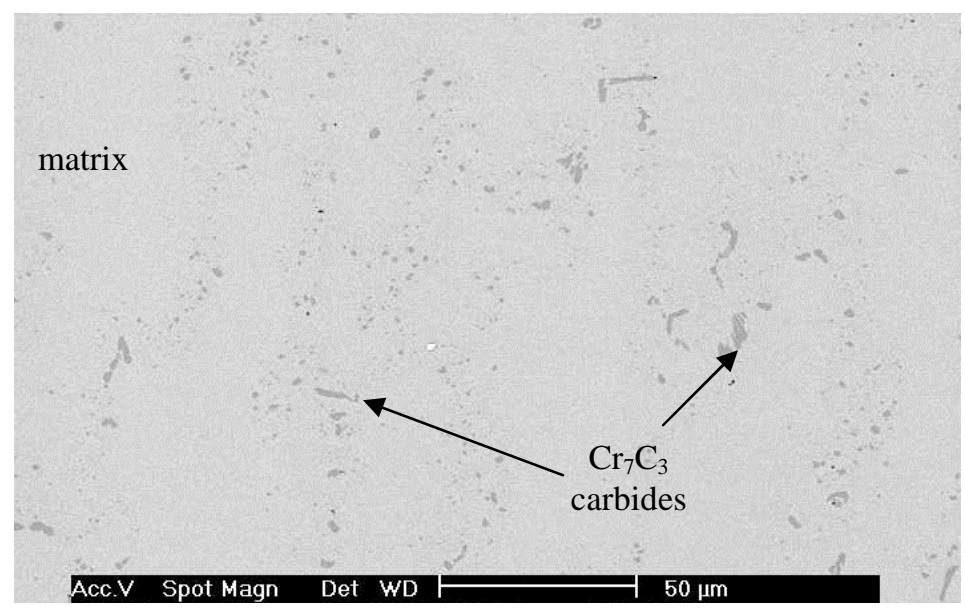

Figure 2 Bulk microstructure of the NiA alloy

\section{Surface Microstructure after Exposure at $1000^{\circ} \mathrm{C}$ for 100 hours}

Near the external surface the NiA alloy microstructure is severely damaged (Fig. 3). From the surface into the bulk, the initial microstructure is replaced with two distinct zones. The outer one, thereafter called "no carbide zone", has completely lost its carbides and is deteriorated by both internal oxidation and appearance of voids. The inner zone now contains some carbides but with a rounder shape, and some newly formed precipitates. The latter exhibit an acicular shape, different sizes and orientations.
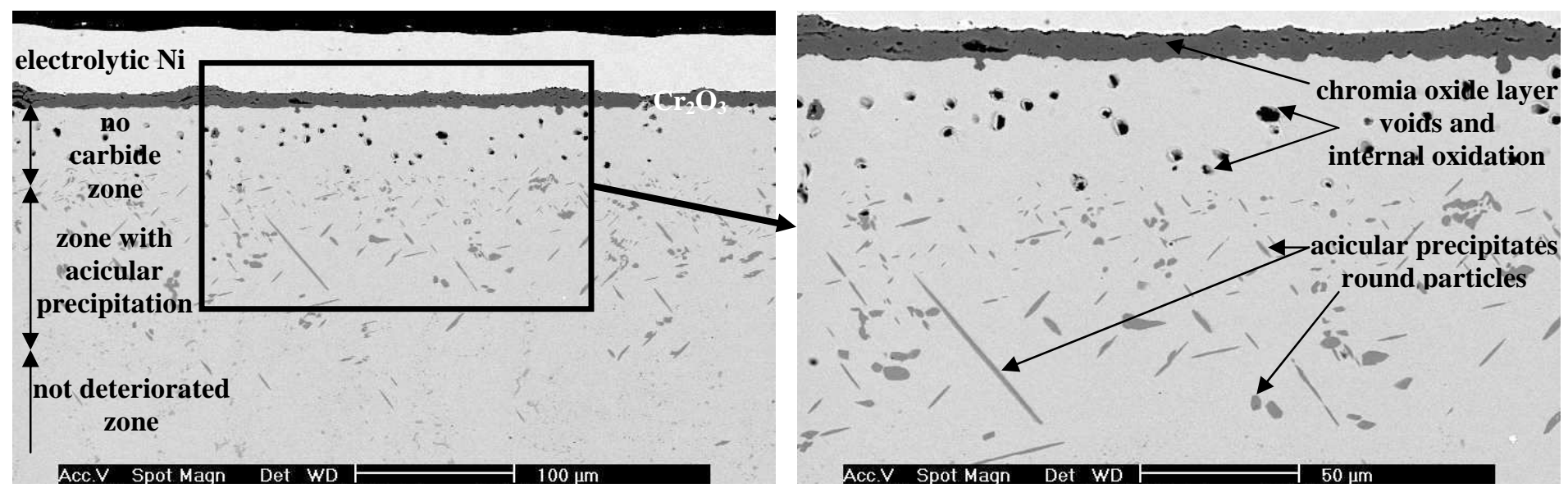

Figure $3 \quad$ Microstructure changes along the oxidation front of $\mathrm{NiA}$ after $100 \mathrm{~h}$ at $1000^{\circ} \mathrm{C}$ 
Spot microanalysis were performed using both EDS and WDS techniques : acicular particles and compact particles seem to be chromium carbides, which explains their dark color in BSE mode. The atomic ratio generally found indicates that these carbides are $\mathrm{Cr}_{7} \mathrm{C}_{3}$ (at different acceleration voltages).

Several chromium profiles, obtained by WDS microanalysis, were compared to the different microstructure zones. It appears that, as illustrated by Fig. 4, the no carbide zone corresponds to a high $\mathrm{Cr}$ gradient and a chromium range of $[21 \% \mathrm{wt}, 26 \% \mathrm{wt}]$ whereas the zone containing acicular carbides exhibits a lower $\mathrm{Cr}$ gradient and higher chromium contents.

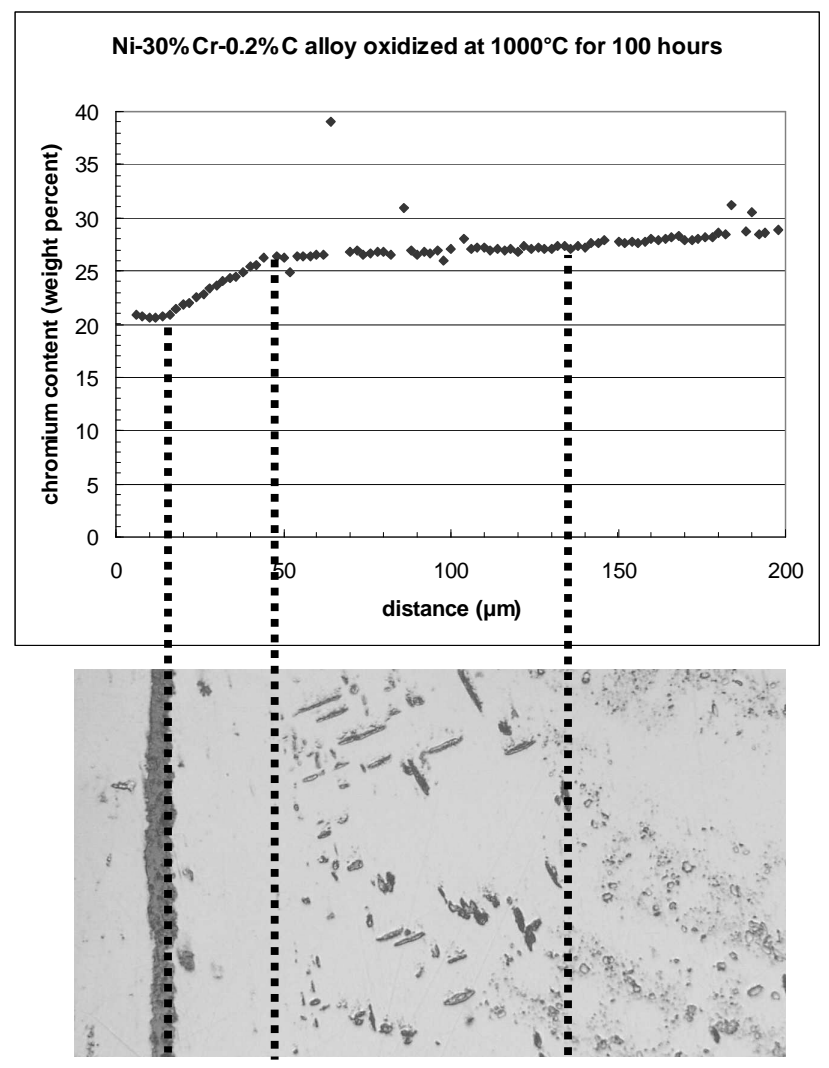

Figure 4 Correspondence between \%wt $\mathrm{Cr}$ profile and the successive microstructures

In addition, SEM photographs at high magnification, like the one presented by Fig. 5, were taken on several areas on the acicular precipitation zone. EDS analysis of the chemical composition was performed on the same area (including matrix and carbides). The six results lead to an average of $\mathrm{f}_{\text {mass }}=4.64 \%$ of carbides and a chromium content of $29.81 \%$ wt.

\section{Thermodynamic Calculations}

Firstly, for the no carbide zone, an isothermal ternary $\mathrm{Ni}-\mathrm{Cr}-\mathrm{C}$ diagram was computed for $\mathrm{T}=1000^{\circ} \mathrm{C}$ (Fig. 6). Considering the nickel-rich corner and the chromium contents measured with WDS profiles through this zone, a range of possible values for \%wt $\mathrm{C}$ was first estimated. Thermo-Calc gave, for the two considered \%wt $\mathrm{Cr}(21$ and 26\%wt $\mathrm{Cr}$ ), the two upper limits for \%wt $\mathrm{C}$ according to the absence of carbides. Thus, the no carbide zone contains less than $0.037 \%$ wt $\mathrm{C}$ close to the surface and less than $0.019 \%$ wt $\mathrm{C}$ on the frontier between the no carbide zone and the acicular carbides zone. Secondly, the average carbon content of the zone with acicular carbides is calculated. Since the average content of $29.81 \mathrm{wt} \% \mathrm{Cr}$ and average $4.64 \%$ mass percent of carbides, the calculated average carbon content is $0.435 \mathrm{wt} \%$, which is higher than the original carbon content of the alloy, $0.2 \mathrm{wt} \%$. 


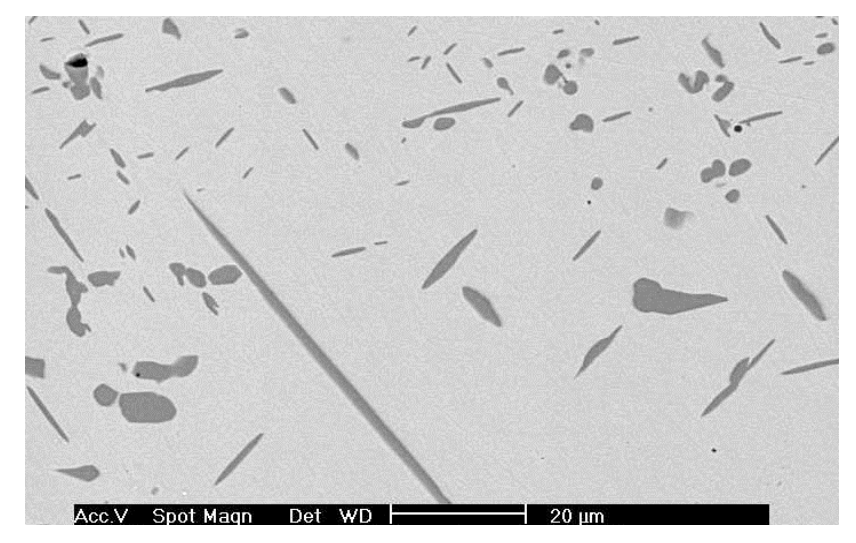

Figure 5 SEM microphotograph at high magnification, taken on a zone with acicular precipitates for image analysis (here $7.50 \%$ surf) ; chemical composition has been determined on this area by EDS microanalysis (here $30.25 \%$ wt $\mathrm{Cr}$ )

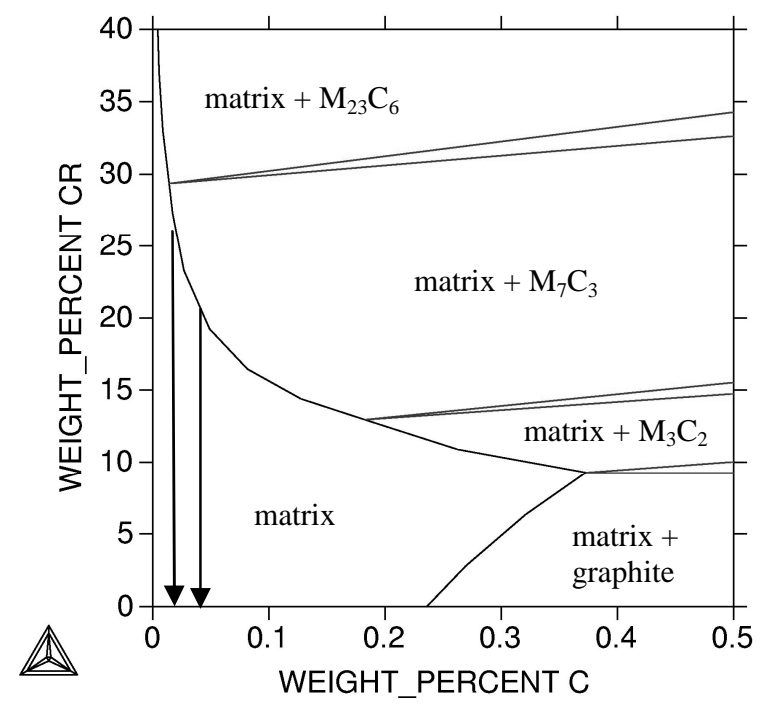

Figure 6 Isothermal ternary Ni-Cr-C diagrams for $\mathrm{T}=1000^{\circ} \mathrm{C}$ (in the Ni-rich corner)

\section{Results of the $\mathrm{CoA}$ and $\mathrm{CoB}$ Cobalt Base Superalloys after Oxidation at ${ }^{1000}{ }^{\circ} \mathrm{C}$}

\section{Bulk Microstructure after Exposure at $1000^{\circ} \mathrm{C}$ for 100 hours}

Microstructure of the bulk is shown by the two SEM photographs in Fig. 7. CoA is composed of an austenitic matrix with spaces between dendrites mainly taken by tantalum carbides $\mathrm{TaC}$ which form an eutectic with matrix. $\mathrm{CoB}$ also exhibits an austenitic matrix but with a grain boundary carbides network composed of both $\mathrm{TaC}$ and $\mathrm{Cr}_{23} \mathrm{C}_{6}$ eutectic carbides. The latter have kept the solidification eutectic morphology of $\mathrm{Cr}_{7} \mathrm{C}_{3}$. $\mathrm{Like}$ for the NiA alloy, phase identifications were performed by microanalysis.

EDS microanalysis on these whole areas gave :

for CoA : - alloy composition : 28.36Cr-9.25Ni-5.4Ta (bal Co) in weight percent - average mass fractions : $5.08 \% \mathrm{TaC}$ and $0.62 \% \mathrm{Cr}_{23} \mathrm{C}_{6}$ 
for $\mathrm{CoB}: \quad$ - alloy composition : 31.66Cr-8.40Ni-5.2Ta (bal Co) in weight percent

- average mass fractions : $4.93 \% \mathrm{TaC}$ and $7.87 \% \mathrm{Cr}_{23} \mathrm{C}_{6}$

The mass fractions calculated by Thermo-Calc with the above alloy compositions are 5.076\% $\mathrm{TaC}$ and $0.584 \% \mathrm{M}_{23} \mathrm{C}_{6}$ for $\mathrm{CoA}$ with $0.37 \%$ wt C. For $\mathrm{CoB}$ they are $4.922 \% \mathrm{TaC}$ and $7.921 \% \mathrm{M}_{23} \mathrm{C}_{6}$ with $0.77 \%$ wt $\mathrm{C}$.
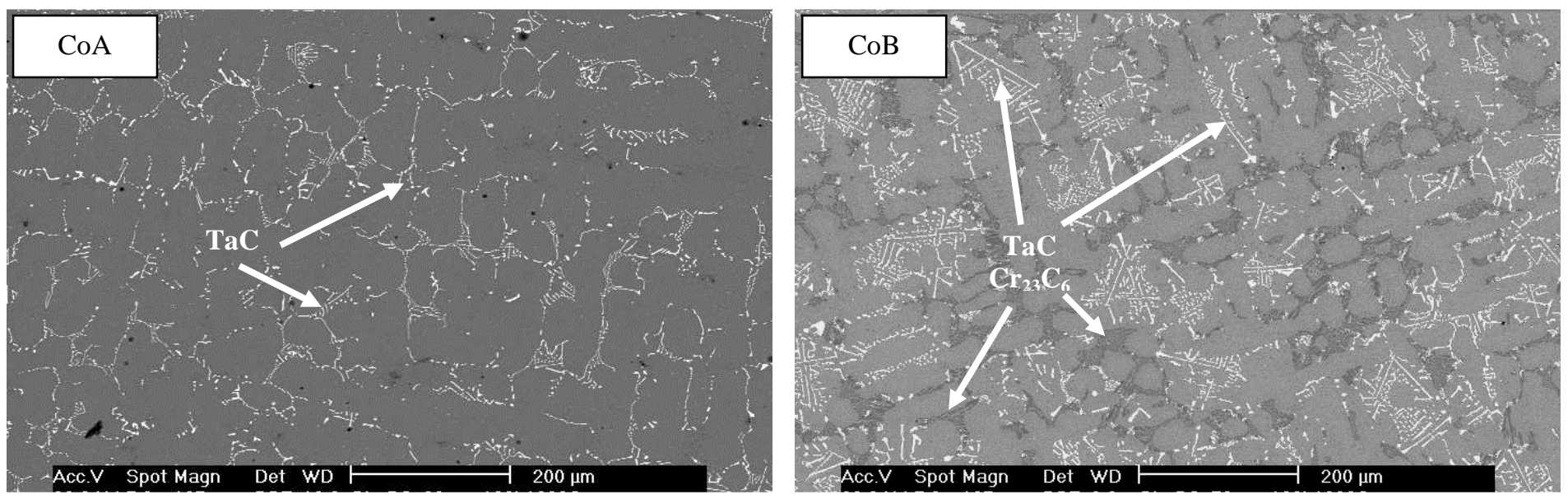

Figure $7 \quad$ Bulk microstructure of the $\mathrm{CoA}$ and $\mathrm{CoB}$ cobalt-base superalloys

\section{Surface Microstructure after Exposure at $1000^{\circ} \mathrm{C}$ for 100 hours}

The $\mathrm{CoA}$ and $\mathrm{CoB}$ alloys exhibit two types of oxidation products : $\mathrm{Cr}_{2} \mathrm{O}_{3}$ mainly as an external layer, and internal $\mathrm{CrTaO}_{4}$ near the surface. In addition, acicular oriented phases appeared in a zone separating a thin outer no carbide zone and the not deteriorated inner zone (Fig. 8 and Fig. 9). WDS and EDS spot analysis demonstrate that these acicular phases are $\mathrm{Cr}_{7} \mathrm{C}_{3}$ carbides. Three points EDS profiles were performed through the no carbide zone, the thickness of which is about $15 \mu \mathrm{m}$ for $\mathrm{CoA}$ and $10 \mu \mathrm{m}$ for $\mathrm{CoB}$. For CoA the Cr content decreases from $22 \%$ wt $\mathrm{Cr}$ (frontier with the neighbor zone which still contains carbides) to $16 \%$ wt $\mathrm{Cr}$ on the extreme surface. The lost of $\mathrm{Cr}$ for $\mathrm{CoB}$ is only about half. Ta decreases from about $1 \%$ wt (significantly less than the initial content in the alloy) to 0 for CoA. It is more difficult to precisely determine the Ta content evolution through the no carbide zone since the measured contents are dispersed, maybe because of the initial carbides in grain boundaries.
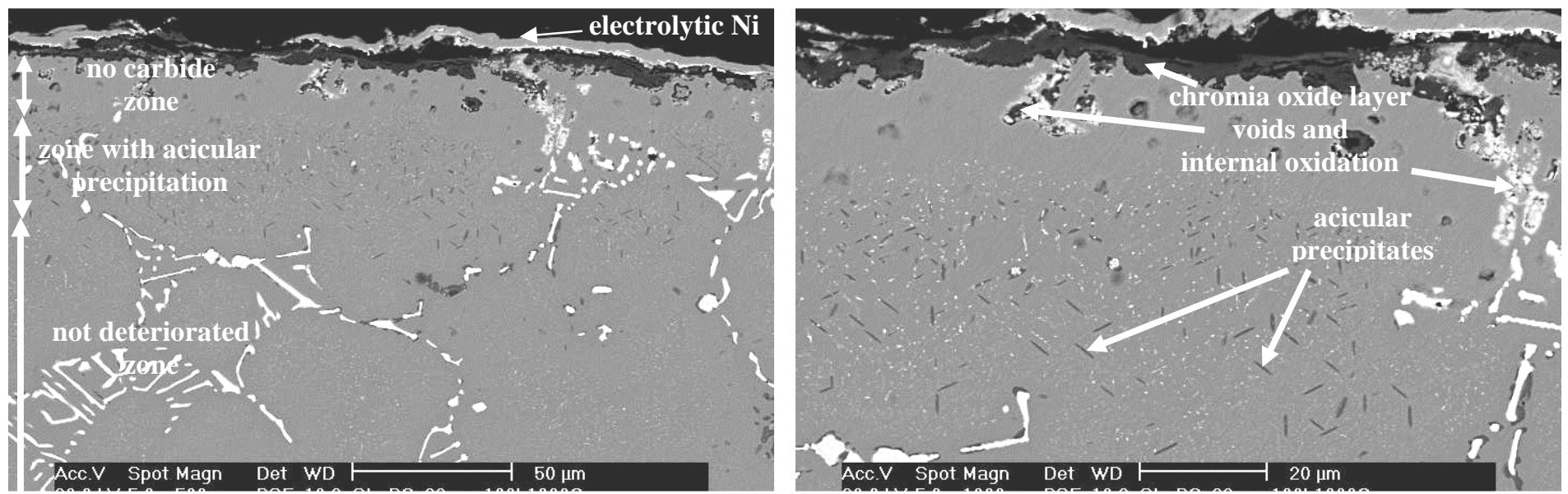

Figure $8 \quad$ Microstructure evolutions along the oxidation front of $\mathrm{CoA}$ after $100 \mathrm{~h}$ at $1000^{\circ} \mathrm{C}$ 

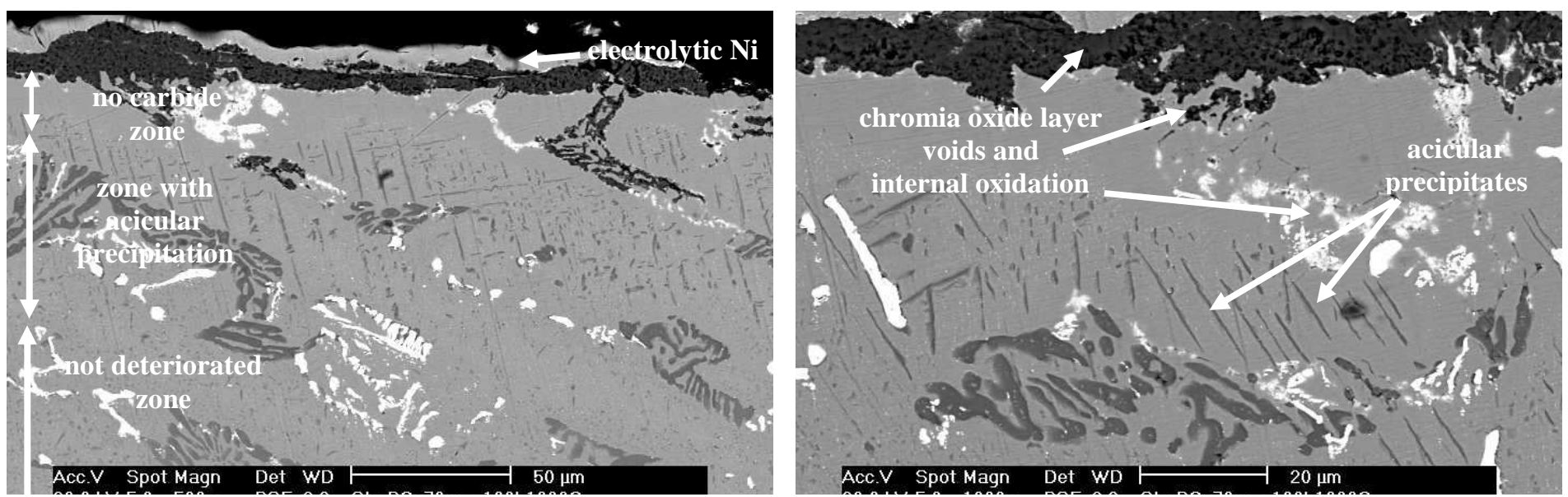

Figure 9 Microstructure evolutions along the oxidation front of $\mathrm{CoB}$ after $100 \mathrm{~h}$ at $1000^{\circ} \mathrm{C}$

As it was done for NiA, several high magnification SEM photographs of limited zones were taken. For each alloy three results of surface phase fractions were obtained and they showed similar values. The left photograph of Fig. 10 corresponds to a zone of CoA containing $\mathrm{f}_{\text {mass }}=2.6 \%$ of $\mathrm{Cr}_{7} \mathrm{C}_{3}$ and $\mathrm{f}_{\text {mass }}=1.6 \%$ of TaC. This zone contains $27.67 \mathrm{Cr}-9.82 \mathrm{Ni}-2.07 \mathrm{Ta}$ (bal Co) in weight percent. The right photograph corresponds to a zone of $\mathrm{CoB}$ containing $\mathrm{f}_{\text {mass }}=8.0 \%$ of $\mathrm{Cr}_{7} \mathrm{C}_{3}$ and $\mathrm{f}_{\text {mass }}=1.2 \%$ of $\mathrm{TaC}$. Its chemical composition measured by EDS is 28.88Cr-9.40Ni-1.61Ta (bal Co), in \%wt.
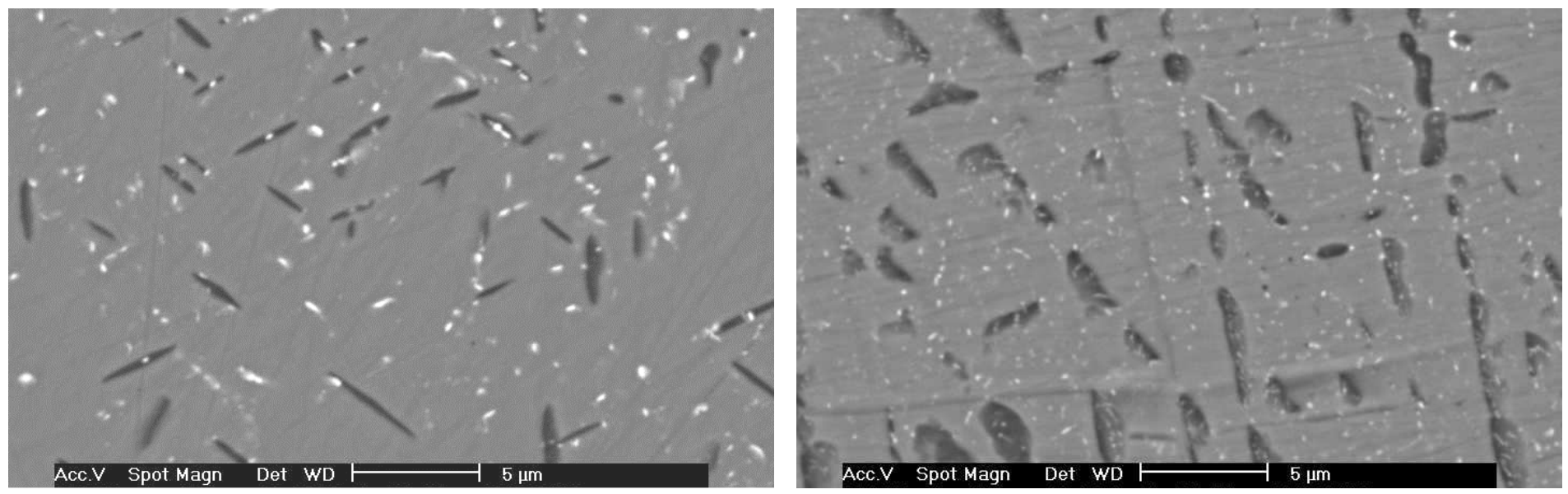

Figure 10

Examples of analyzed (by EDS and image analysis) areas taken inside the zones containing only acicular new $\mathrm{Cr}_{7} \mathrm{C}_{3}$ carbides and secondary $\mathrm{TaC}$ carbides in the cases of $\mathrm{CoA}$ (left) and $\mathrm{CoB}$ (right)

\section{Thermodynamic Calculations}

Like for NiA the no carbide zone was first considered. For CoA, the absence of any carbides in the extreme surface, where a spot EDS analysis gave the 15.82Cr-12.30Ni-0.01Ta (bal Co) composition, indicates that the carbon weight content must be lower than $0.076 \%$ wt $\mathrm{C}$. At the other frontier of the no carbide zone, where EDS found $20.32 \mathrm{Cr}-10.77 \mathrm{Ni}-0.94 \mathrm{Ta}$ (bal Co), the carbon content must be lower than $0.050 \%$ wt $\mathrm{C}$. These values are about ten times smaller than the $\mathrm{C}$ content of the initial CoA alloy.

This type of calculation made for $\mathrm{CoB}$ lead to a content smaller than $0.061 \%$ wt $\mathrm{C}$ for the extreme surface (the composition of which is $17.95 \mathrm{Cr}-11.51 \mathrm{Ni}-0.97 \mathrm{Ta}-\mathrm{bal} \mathrm{Co}$ ) and smaller than $0.019 \%$ wt $\mathrm{C}$ for the other 
frontier (where composition is $20.60 \mathrm{Cr}-10.52 \mathrm{Ni}-1.63 \mathrm{Ta}-\mathrm{bal} \mathrm{Co}$ ), which between ten and twenty times smaller than for the initial CoB alloy.

Furthermore, we have performed calculations on the compositions of the two zones photographed in Fig. 10. For the CoA zone, calculations, based on the 27.67Cr-9.82Ni-2.07Ta-bal Co composition (\%wt), converged to the experimental mass fractions of phases resulting from image analysis $\left(\mathrm{f}_{\text {mass }}=2.6 \%\right.$ of $\mathrm{Cr}_{23} \mathrm{C}_{6}$ and $\mathrm{f}_{\text {mass }}=1.7 \%$ of $\mathrm{TaC}$ ) for $0.27 \% \mathrm{wt} \mathrm{C}$. The final calculation results gave $\mathrm{f}_{\text {mass }}=2.6 \%$ of $\mathrm{Cr}_{23} \mathrm{C}_{6}$ and $\mathrm{f}_{\text {mass }}=1.6 \%$ of TaC.

For the $\mathrm{CoB}$ zone, calculation based on the $28.88 \mathrm{Cr}-9.40 \mathrm{Ni}-1.61 \mathrm{Ta}-\mathrm{bal} \mathrm{Co}(\% \mathrm{wt})$ composition and the experimental mass fractions $\left(8.0 \% \mathrm{Cr}_{23} \mathrm{C}_{6}\right.$ and $\left.1.2 \% \mathrm{TaC}\right)$ gives the carbon content of $0.55 \% \mathrm{C}$.

\section{Some Results Obtained at Higher Temperatures}

The NiA and CoA alloys were also oxidized at higher temperatures, $1100^{\circ} \mathrm{C}$ for the former and $1200^{\circ} \mathrm{C}$ for the latter. The surface microstructures are illustrated by Fig. 11 and Fig. 12, which also present a WDS chromium profile and three EDS spot analysis results respectively. First it can be observed that the chromia external layer is twice as thick as for $1000^{\circ} \mathrm{C}$. This results from the increased oxidation rate due to the higher temperature.

Contrary to what was observed for $1000^{\circ} \mathrm{C}$, the deteriorated zone of NiA seems to be only composed of the no carbide zone, with no acicular phase present. Moreover, the depth of the no carbide zone appears as being three times as great as the one resulting from oxidation at $1000^{\circ} \mathrm{C}$. From the bulk, the WDS chromium content profile shows that the chromium content decreases from $31 \%$ wt $\mathrm{Cr}$ to about $25 \%$ wt $\mathrm{Cr}$. Isothermal $1100^{\circ} \mathrm{C}$ ternary diagrams were obtained using Thermo-Calc. On these diagrams, the absence of any other phases than matrix indicates that the carbon content must be lower than $0.054 \%$ wt $\mathrm{C}$ at the extreme surface and lower than $0.025 \%$ wt $\mathrm{C}$ at the junction of the no carbide zone and the bulk. Thus, this zone of the sample has lost a great part of its initial carbon content. Everywhere else in the sample, the carbide surface fraction is the same as in the bulk. This indicates that no other regions became enriched with a part of carbon lost by the deteriorated zone.
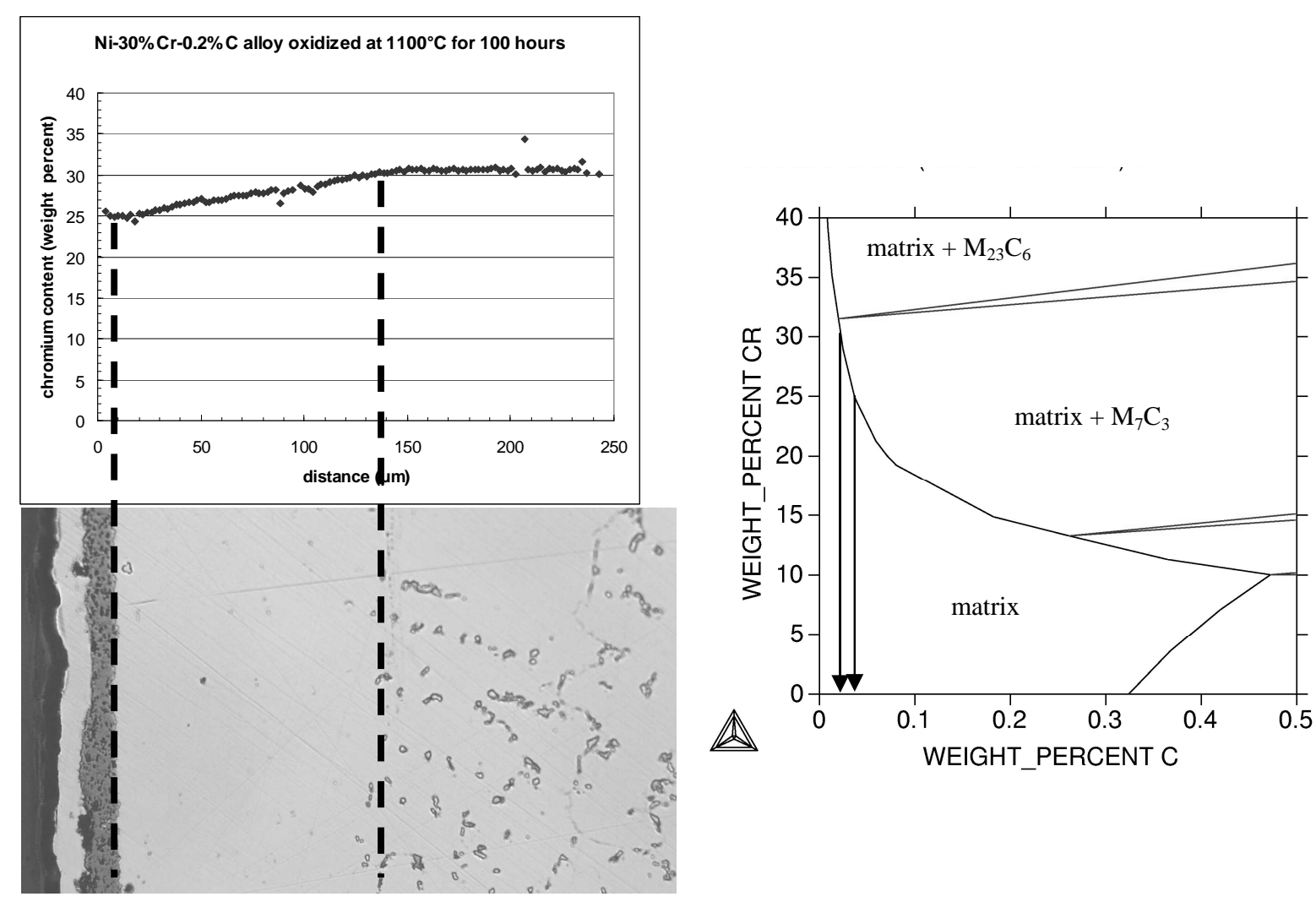

Figure 11 Surface microstructure of NiA alloy after $100 \mathrm{~h}$ oxidation at $1100^{\circ} \mathrm{C}$ and resulting maximal carbon contents given by ThermoCalc calculations 


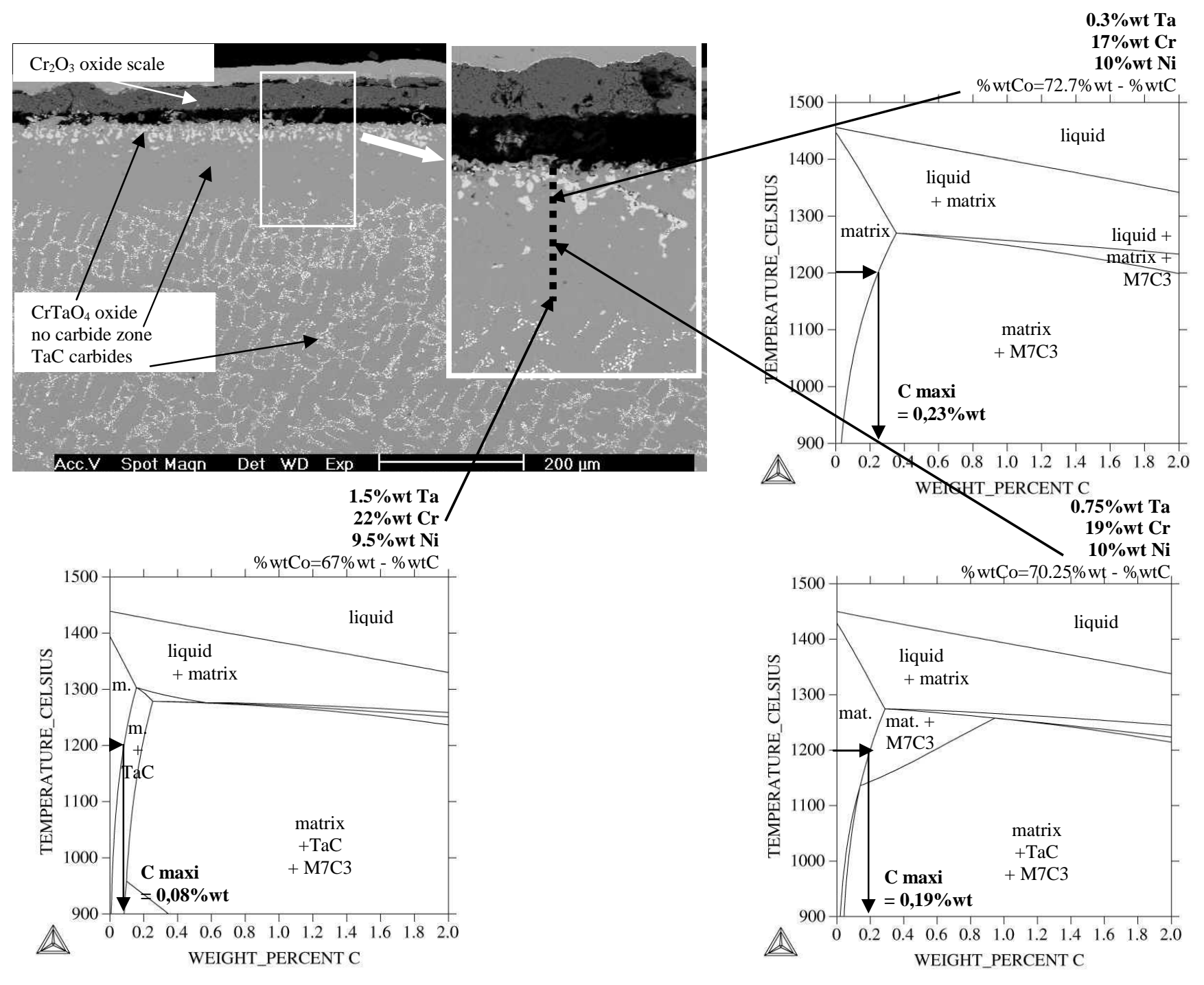

Figure 12 Surface microstructure of CoA alloy after $100 \mathrm{~h}$ oxidation at $1200^{\circ} \mathrm{C}$ and resulting maximal carbon contents given by Thermo-Calc calculations

After oxidation at $1200^{\circ} \mathrm{C}, \mathrm{CoA}$ exhibits an external chromia layer which is four times thicker. Like for $\mathrm{NiA}$ at $1100^{\circ} \mathrm{C}$, it can be seen here a deeper no carbide zone, without any acicular new precipitates. In the case of this complex alloy (regarding the chemical composition), diagrams such as for $\mathrm{NiA}$ are not possible. Nevertheless three diagrams were calculated in Fig. 12 for the fixed Ta-Cr-Ni compositions, measured by spot EDS analysis, on three points across the no carbide zone. From the external zone towards the beginning of the bulk the maximal possible carbon content decreases from $0.23 \%$ wt $\mathrm{C}$ down to $0.08 \%$ wt $\mathrm{C}$. Here too no carbon enriched zone was seen all over the bulk.

\section{Interpretations and Discussion}

There is a no carbide zone in all the three alloys studied. Its existence is possible only if carbon is smaller than certain very low values. For $\mathrm{NiA}$ oxidized at $1000^{\circ} \mathrm{C}$, the latter can be considered as negligible compared to carbon contents of initial alloys and of neighboring zones containing old or new carbides. Then, it can be considered that, on the one hand this zone has almost lost all its carbon atoms. On the other hand, the zone in which acicular carbides appeared exhibits a higher carbon content that the initial one. Since bulk presents the initial carbon content $(0.20 \%$ wt $\mathrm{C})$, the additional carbon necessary comes from the zone which has lost its carbides. 
At that time it appears that a balance sheet has to be drawn up. It is possible to simplify the carbon content profile through the deteriorated zone as described in Fig. 13. Two versions can be proposed : one with a linear interpolation over the <acicular carbides zone / bulk> frontier line (first hypothesis, black lines), and one considering that the carbon content falls more quickly from $0.435 \%$ to $0.20 \%$ at the same location (second hypothesis, gray lines).

Considering the first hypothesis, the carbon content of the deteriorated zone is estimated using the formula (2), while the formula (3) could be selected for the second hypothesis.

Mass of carbon $=(\mathrm{S} . \mathrm{\rho}) \cdot \sum_{\mathrm{i}=1}^{2}\left[\left(\mathrm{e}_{\mathrm{i}} \cdot \% \mathrm{wt} \mathrm{C}_{\mathrm{i}}\right)+\mathrm{e}_{3} \cdot\left(\frac{\% \mathrm{wt} \mathrm{C_{2 }}+\% \mathrm{wt} \mathrm{C}_{3}}{2}\right)\right]$

Mass of carbon $=(\mathrm{S} . \rho) \cdot \sum_{\mathrm{i}=1}^{3}\left(\mathrm{e}_{\mathrm{i}} \cdot \% \mathrm{wt} \mathrm{C}_{\mathrm{i}}\right)$

where $S$ is the considered surface (e.g. $1 \mathrm{~cm}^{2}$ ), $\rho$ is the alloy density (about $8.9 \mathrm{~g} . \mathrm{cm}^{-3}$ ); $\mathrm{e}_{\mathrm{i}}$ and $\%$ wt $\mathrm{C}_{\mathrm{i}}$ are defined in Fig. 13.

For $1 \mathrm{~cm}^{2}$ of external surface, we find about $0.35 \mathrm{mg}$ of $\mathrm{C}$ for the first hypothesis and $0.30 \mathrm{mg}$ of $\mathrm{C}$ for the second one. These very approximated values have to be compared to the initial carbon mass contained in the same volume, which equals to $0.27 \mathrm{mg}$. It seems that the second hypothesis is the best of the two ones. Then, almost all the carbon lost by the no carbide zone came into the matrix more deeper in the alloy. This carbon left the grain boundary chromium carbides, the decomposition of which was promoted by the diffusion of chromium

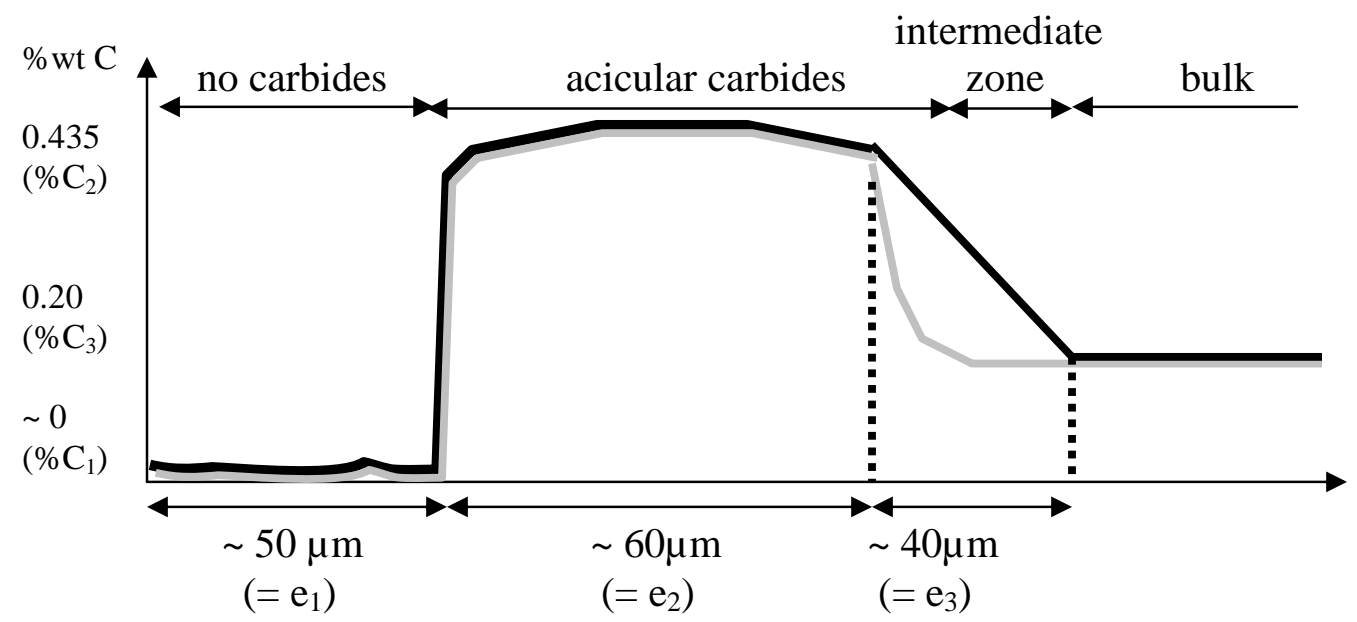

Figure 13 Scheme of the carbon content profile through the deteriorated zone of NiA oxidized at $1000^{\circ} \mathrm{C}$

towards the oxidation front. Thereafter, they entered into the matrix and met chromium atoms present in solid solution. There they formed with chromium atoms new carbides which precipitated in matrix with an acicular shape and an orientation which is maybe related to the crystallographic axis of the FCC austenitic network. These acicular carbides may coexist with the initial grain boundary carbides which have not yet disappeared and which have a more compact shape. They lead to a local surface fraction of carbides which is significantly higher than in the bulk. This was first qualitatively seen by microscope examinations and second quantitatively measured by image analysis.

At $1100^{\circ} \mathrm{C}$, the mechanisms would not be the same, since no carbon enrichment can be noted elsewhere in the alloy. Carbon lost by decomposition of the initial grain boundary carbides disappears, without any doubt being oxidized into $\mathrm{CO}$ or $\mathrm{CO}_{2}$ gases. For $1 \mathrm{~cm}^{2}$ of NiA external surface and a no carbide zone of about $100 \mu \mathrm{m}$ in which carbon content is negligible, the same type of calculation as before leads to a carbon mass lost of $180 \mathrm{mg}$ that became gas. 
It is also possible that both mechanisms exist. Then, the matrix enrichment with carbon would be dominant at $1000^{\circ} \mathrm{C}$ while disappearance of carbon by oxidation into gas would become dominant at higher temperatures.

Unfortunately, such calculations are not really possible for the CoA and CoB industrial superalloys. Indeed, zones with acicular precipitated carbides are often partially mixed in their inner part with remaining grain boundary carbides and it is difficult to be precise. But new acicular $\mathrm{Cr}_{7} \mathrm{C}_{3}$ carbides also appear among the initial $\mathrm{TaC}$ secondary carbides for $\mathrm{CoA}$, and among the pre-existing secondary $\mathrm{TaC}$ and $\mathrm{Cr}_{7} \mathrm{C}_{3}$ for $\mathrm{CoB}$. In the two cases it is a consequence of an increase of the total carbon contained in the matrix alone. This clearly shows that the mechanism of integration of carbon into matrix also acts here. In addition, for CoA, it was seen that a raising of the oxidation temperature unable this phenomenon which is probably also replaced by a disappearance of carbon from the alloy (becoming oxidized into gases).

After the presentation of all these observations, results and interpretations, we can finish by underlining that thermodynamic modeling, associated to microstructure phase quantitative analysis and microanalysis, was of a good help to better characterize and understand what it happened to our specific superalloys. This method allowed to supply the lack of microanalysis techniques for what quantitative measurements of contents for light and rare elements is a real problem. With this particular procedure it became possible to localize carbon, which is an element of a great importance in our superalloys. Consequently curious phenomena have been explained. But resulting quantitative data need to be carefully given. The good agreement between the aimed composition of the alloy and the quantitative microstructure showed first that the employed method allows a good accuracy. Nevertheless, other determinations are more difficult. Image analysis for fine secondary TaC carbides must be made taking into account that the visibility of secondary $\mathrm{TaC}$ existing just under the sample surface can give a white point. But it is true that they can also influence the EDS results. Thus we have chosen to consider our EDS results, and to take, among the fine white carbides, only those that were very white.

Let us remark that choosing a simple nickel base alloy allowed to simplify the problem from the more complex alloys like the industrial one (Fig. 1). The different zones were clearly evidenced and sufficiently separated each other to allow good estimations of both EDS measurements and surface analysis ones, for a better correspondence between the two. After having understood the phenomena with this simple alloy, we were in better conditions to understand what it happened in the multi-component cobalt base superalloys.

\section{Conclusion}

During their use at high temperature superalloys are oxidized by hot gases, notably by air's oxygen. The results of this surface attack are first external and internal selective oxidation. But they can encounter also other phenomena potentially important for alloy mechanical properties near the external surface. This was seen in this work in three cast alloys belonging both to two complexity families and two main types of superalloys. Among these phenomena it can be found, for these carbide strengthened superalloys, the lost of grain boundary carbides and of secondary carbides, on a depth increasing with temperature. It was also especially revealed for the $1000^{\circ} \mathrm{C}$ case the precipitation, by solid state phase transformation, of acicular carbides inside the matrix. It appeared that this reaction involved carbon, coming from disappearing grain boundary carbides and diffusing inwards the matrix. There they join chromium atoms already present here in solid solution. This interesting phenomenon does not exist (or is not dominant) at temperature sufficiently higher : carbon mainly leaves the alloy, probably being oxidized into gases.

Thermodynamic modeling was revealed as a very precious tool, complementary to more classical equipment when oxidation phenomena are studied. It allows to precise the last remaining unknown quantities that are light elements contents.

\section{References}

1. $\quad$ E. F. Bradley, Superalloys : A Technical Guide, ASM International, 1988.

2. C. T. Sims and W. C. Hagel, The Superalloys, John Wiley \& Sons, 1972.

3. D. Landolt, Corrosion et Chimie de Surfaces des Métaux. Traité des Matériaux (12), Presses Polytechniques et Universitaires Romandes, 1997. 
4. $\quad$ P. Kofstad, High Temperature Corrosion, Elsevier applied science, 1988.

5. J. Di Martino, C. Rapin, P. Berthod, R. Podor and P. Steinmetz, Corrosion Science (in press)

6. $\quad H a n d b o o k$ of Chemistry and Physics, $57^{\text {th }}$ edition (1976-1977)

7. Thermo-Calc version N or Win NT: "Foundation for Computational Thermodynamics" Stockholm, Sweden, Copyright $(1993,2000)$

8. $\quad$ SGTE: "Scientific Group Thermodata Europe" database, update 1992.

9. K. Frisk and A. Fernandez Guillermet, Journal of Alloys and Compounds, 238 (1996) 167-179.

10. $\quad$ Z.-K. Liu and Y. Austin Chang, CALPHAD, 23 (1999) 339-356.

11. I. Ansara and M. Selleby, CALPHAD, 18 (1994) 99-107.

12. $\quad$ N. Dupin and I. Ansara, Journal of Phase Equilibria, 14 (1993) 451-456.

13. L. Dumitrescu, M. Ekroth and B. Jansson, Metallurgical and Materials Transactions A, 32A (2001) 2167-2174.

14. $\quad$ N. Dupin and I. Ansara, Z. Metallkd., 87 (1996) 555-561. 